\title{
Quality of Life among Parents of Children with Autism Spectrum Disorder in Riyadh
}

\author{
Khaled Yousef Asi (Corresponding author) \\ College of Social Sciences, Al-Imam Muhammad Ibn Saud Islamic University \\ Saudi Arabia \\ E-mail: khaled-asi@hotmail.com
}

Received: April 31, 2016 Accepted: September 18, $2016 \quad$ Published: September 20, 2016

doi:10.5296/ire.v4i2.9958 URL: http://dx.doi.org/10.5296/ire.v4i2.9958

\begin{abstract}
The current study aimed to identify the level of quality of life among parents of children with autism spectrum disorder and the differences according to the relationship with the autistic child, gender, severity of disability. The sample consisted of (100) parents of children with autism spectrum disorder, enrolled in the program of autism, intentionally selected in Riyadh, Saudi Arabia. Quality of life scale prepared and utilized by the author after verification of validity and reliability. The results showed that the level of quality of life among the participants was medium, and the results showed statistically significant differences in the level of quality of life among the participants due to the impact of the relationship with autistic children, where differences were in favor of the parents, and the variable of gender of the autistic child, where differences were in favor of the males, and severity of the disability, where the differences were in favor of the mild group. The study recommended the need to draw the attention of officials in the care and service centers for children with autism spectrum to provide training programs and activities for parents of autistic children to raise the level of quality of life, especially mothers.
\end{abstract}

Keywords: Quality of life, parents of children with autism spectrum disorder

\section{Introduction:}

The family's role is fundamental in the formation of the child's personality, representing the first social surrounding; the family plays an important role in developing the child's abilities and skills, and perhaps the presence of a disabled child in the family may represent a change point in lives of the entire family, it reorganize the life and priorities for coping with new circumstances. Perhaps the presence of a disabled child in the family in general and children 
with autism spectrum disorder in particular, could result in many of the psychological stress, problems and challenges requiring them to contend with all conditions and circumstances that occur in the family as a result of the presence of a disabled child among them.

To think about the lives of the disabled, it is noted that disability has negative side effects on the various aspects of life of the disabled individuals in various life cycle, some of which is linked to disability they have, or the family environment in which they live, their economic and social circumstances, educational environment they learn, or their cultural aspects, which would affect the quality of life of these individuals and their families (Muhammad, 2011).

Quality of Life is one of the modern terms in the field of psychology, which represents a new trend since the nineties of the last century by Martin Seligman, known as (Positive Psychological); and who sees the man quite different, and that health is the origin, not a disease, and that man can adapt to and comply with the society if they focused on the positive aspects in their life, hope, optimism, happiness and self-satisfaction, and enjoy relationships with others, as well as mental flexibility (Abdullah, 2014). Magdi (2009) indicated that the concept of quality of life is in the circle of what is known as the science of positive psychology, which develops the individual's feelings of satisfaction and optimism within the limits of available conditions and potentialities. Quality of Life, as a concept, has a different meaning for a patient who wishes speed recovery than an individual who wishes success in a test, feelings of satisfaction and optimism for each is the same when achieved, but the desired is completely different.

Abu Halawa (2010) confirmed that quality of life widely received more attention both in theory and practice due to differing views among researchers about the this concept. Alkhenji (2006) and Al-Adly (2006) pointed that the quality of life varies from one individual to another, based on what is needed in the circle of life and requirements. Bonomi, Patrick \& Bushnel (2000) pointed that the concept of quality of life has wide usage and is linked to the psychological and health state of the individual and his ability to be autonomous and how his social and environmental interaction is. Reine, et al (2003) pointed out that the concept of quality of life is affected by the events of life experienced by the individual, which emphasizes that the individual sense of satisfaction and happiness involved within the circle of the current living conditions, while Iraqi and Mazloum $(2005,471)$ defined quality of life as "an individual's awareness to achieve an equilibrium between the physical, emotional and social aspects for achieving satisfaction with life, enjoy it and positive existence; the quality of life expresses the psychological adjustment of living conditions and self-perception of life".

In sum, the quality of life can be theoretically defined within the framework of this study, as the degree of satisfaction felt by parents of children with autism spectrum disorder towards the various dimensions of life as the level of satisfaction with life, physical and mental health, and satisfaction with material and moral sides, interaction with the family and social relations, getting social support, practice of daily activities, the ability to pursue happiness and optimism resulted from the psychological readiness of the individual, and the role of 
others and their ability to provide support for parents to interact with the surrounding environment.

In this connection, it can be said that sense of low quality of life among parents of children with autism spectrum disorder may later lead to many and various problems in their lives such as anxiety and introversion, social withdrawal, a sense of loneliness and loss of the meaning of life, the lack of efficiency in social relations and negative social behavior, and the failure to form and maintain friendships, emotional unbalance and others.

Many studies have confirmed the existence of a correlation in quality of life between parents and children; when the quality of life is improved among mothers, their ability to deal with their children with disabilities increased, which emphasizes that the quality of life cannot be achieved for individuals with disabilities without achieving it among their parents (Alashwal, 2005). Quality of life can be achieved for the family if their needs have been satisfied, through the various fields such as the financial condition, the family interaction and enjoy a healthy social life (Park, 2003)

For confirmation, Antle (2005) revealed the positive correlation relationship between the family compatibility and the quality of life through the dimension of rational thinking. Abdel Fattah and Hussein (2006) emphasized the importance of family factor and available sources to improve the quality of life, which examined the family, school and community factors predicting quality of life. DeGrace and Imms (2006) showed that the level of quality of life among the families of children with autism spectrum disorder was medium, and there were differences in the level of quality of life due to severity of the disability in favor of families of children with mild autism. The results of the study of Lee, Harrington, Louie, \& Newschaffer (2008) showed future fears and anxiety among the families of children with autism spectrum disorder leading to poor level of quality of life. Nina, James, Jean \& Ann (2009) investigated the quality of life among families of individuals with and without disabilities, where the authors prepared the quality of life scale for families within the four key domains: family interaction, emotional, physical and financial welfare, and the results showed a significant decrease in the above-mentioned domains.

Institute of Allied Health Sciences and, Department of Nursing, National Cheng Kung University, Taiwan (2009) conducted a study on the quality of life and its relationship with the sense of the mothers of children with autism disorder, where the sample consisted of (114) mothers, a questionnaire utilized including four domains: psychological, physical, environmental and financial domains, and the results showed negative feelings toward psychological and environmental domains. Lundy (2011) indicated that the level of quality of life among the families of children with autism spectrum disorder was medium. Hartley, et al (2012) confirmed that there were differences in the level of quality of life due to the relationship to children with autism spectrum disorder in favor of the parents. Kheir, et al (2012) emphasized on the existence of differences in the level of quality of life for families of children with autism due to the severity of autism spectrum disorder in favor of the mild disorder. Yamada, et al (2012) stressed that the level of quality of life among families of children with unspecific developmental disorders was low, while the results of the Dardas 
and Ahmad (2014), which aimed to detect the level of quality of life among families of children with autistic spectrum disorders, have shown that there were no significant differences between fathers and mothers in the physical, psychological, social and environmental conditions, and stressed that the quality of life was low. Perumal, Veeraraghavan, Lekhra (2014) confirmed that the level of quality of life among families of children with autism spectrum disorder was low.

Moreover, the pessimistic outlook among parents of children with autism spectrum disorder and their expectations of negative future events lead to a poor level of quality of life, which may also be reflected on their disabled children and may remain with them as a permanent feature. Quality of life is one of the positive factors that give the families of the disabled the ability to carry on and appetite for life and full responsibility for its requirements and coping with the disability of their children. Hence, it is needed to conduct the current study, which sought to identify the level of quality of life among parents of children with autism spectrum disorder in Saudi Arabia.

\section{Statement of the problem and questions:}

Although many pieces of literature review addressed the quality of life in a globally and regionally research, they are lacking theoretical research, which studied this term with the parents of children with autism spectrum disorder at the local level in Saudi Arabia. Thus, the current study revealed the problem that lies in answering the following questions:

1. What is the level of quality of life among parents of children with autism spectrum disorder?

2. Is there any statistically significant differences $(a=0.05)$ in the level of quality of life among parents of children with autism spectrum disorder due to the relationship with the disabled child?

3. Are there any statistically significant differences $(a=0.05)$ in the level of quality of life among parents of children with autism spectrum due to the gender of the disabled child?

4. Are there any statistically significant differences $(a=0.05)$ in the level of quality of life among parents of children with autism spectrum disorder attributed to the severity of disability?

\section{Significance:}

This study highlights the importance of identifying the level of quality of life among parents of children with autism spectrum disorder. Pieces of literature review included in this study represents an important addition to the Arab library, and contributes to increasing human knowledge about the quality of life among families of children with autism spectrum disorder. This study may brief officials of education and care centers for children with special needs in general and autism spectrum disorder is particular on the importance of the quality of life for families; which contributes to the development of plans, programs and tools that help meet the needs of families of children with special needs and spectrum disorder autism in particular. 


\section{Methodology}

Descriptive and survey approach adopted in the current survey, which qualitatively and quantitatively depicts the reality through answering the questions of the study through quality of life scale.

\subsection{Population and Sampling}

The study population consisted of all the fathers and mothers of children with autism spectrum disorder in the city of Riyadh in Saudi Arabia, while the study sample consisted of (100) parents of children with autism spectrum disorder enrolled in autism program, intentionally chosen in the second semester for the academic year 2015/2016. The participants were distributed according to the relationship with disabled children, gender and severity of disability, as illustrated in Table (1).

Table 1. Distribution of study sample according to the variables

\begin{tabular}{|c|c|c|c|}
\hline Variables & Groups & Frequency & Percentage \\
\hline $\begin{array}{c}\text { Relationship } \\
\text { with disabled } \\
\text { child }\end{array}$ & Father & 51 & 51.0 \\
\cline { 2 - 4 } Gender & Mother & 49 & 49.0 \\
\hline \multirow{2}{*}{$\begin{array}{c}\text { Severity of } \\
\text { disability }\end{array}$} & Male & 50 & 50.0 \\
\hline \multirow{2}{*}{ Female } & Mild & 30 & 50.0 \\
\hline & Moderate & 35 & 32.0 \\
\hline & Severe & 33 & 35.0 \\
\hline
\end{tabular}

\subsection{Instrument}

Quality of life scale designed after reviewing the standards used in the pieces of literature on the quality of life among families of disabled children, the current study based principally on the scales used in the study of Eraqa (2006), Abdul Qadir (2013) and Taha (2013). The final draft of the instrument consisted of (50) paragraphs, distributed to six domains: the quality of public health including (1-8) paragraphs, the quality of family and social life (9-16), the 
quality of emotions (17-25), the quality of mental health (26-36), the quality of activities of daily life (37-44) and financial status (45-50). The responder checks each paragraph on a scale of three degrees, namely, (always, sometimes, and rarely), the scale corrected by giving the following weights, respectively $(3,2$, and 1$)$ for the above mentioned degrees, to reflect those values in the case of negative paragraphs: $(2,3,4,5,6,8,9,11,12,14,16,18,20,21$, $22,24,26,28,30,32,34.36,39,42,45,46,47,48,49$ and 50)

\section{Validity}

To verify the validity of the quality of life scale, the first draft was reviewed and evaluated by ten reviewers, more experienced in special education, psychology and measurement and evaluation in Saudi Universities, where they were asked to check the appropriateness of the paragraphs (items) and to make sure of the language and the appropriateness of the instrument to achieve the study objectives. In light of the views and suggestions of the evaluators, the required modifications were made with agreement percentage $(80 \%)$, and the final draft consisted of (50) paragraphs.

\section{Reliability}

The reliability of the scale was verified by the method of (test-retest), where it was applied to a pilot sample numbered (25) parents of children with autism spectrum disorder in the city of Riyadh, with two weeks interval between first and second application/test. Pearson correlation coefficient was calculated between the scores of respondents and the total reliability coefficient of the instrument was (0.85). The second method conducted by calculating of the internal consistency coefficient (Cronbach's Alpha) of the total scale = (0.91). These are considered appropriate values for achieving the objectives of the study.

\section{Correction for instrument response}

The following statistical criterion utilized for estimating the level of the respondent on the quality of life scale through using the following equation:

Group length $=\underline{\text { Maximum regression }- \text { Minimum regression }}=5-1 / 3=4 / 3=1.33$

Number of Categories 33

(1-2.33) is low, (2.34-less than 3.67) is medium, and (more than 3.67) is high.

\section{Results:}

Results of the first question: What is the level of quality of life among parents of children with autism spectrum disorder? To answer this question, arithmetic means and standard deviations calculated for the level of quality of life among parents of children with autism spectrum disorder, as shown in Table (2). 


\section{Macrothink}

International Research in Education

ISSN 2327-5499

2016, Vol. 4, No. 2

Table (2): the arithmetic means and standard deviations for level of the quality of life among parents of children with autism spectrum disorder in descending order according to means

\begin{tabular}{|c|c|l|c|c|c|}
\hline Rank & No & \multicolumn{1}{|c|}{ Domain } & Mean & St. D & Level \\
\hline 1 & 4 & Quality of mental health & 2.01 & 0.42 & Medium \\
\hline 2 & 3 & Quality of emotions & 1.94 & 0.48 & Medium \\
\hline 3 & 2 & Quality of family and social life & 1.92 & 0.34 & Medium \\
\hline 4 & 5 & Quality of daily activities & 1.89 & 0.30 & Medium \\
\hline 5 & 1 & Quality of public health & 1.87 & 0.50 & Medium \\
\hline 6 & 6 & Financial status & 1.68 & 0.63 & Medium \\
\hline & & Total & 1.90 & 0.34 & Medium \\
\hline
\end{tabular}

Table (2) showed that the arithmetic mean of the domains of quality of life among the participants ranged between (1.68) and (2.01), where the domain of quality of mental health ranked the first with the highest mean (2.01) and a standard deviation (0.42) and medium level for quality of life, while the domain of financial status got the sixth place with a mean (1.68) and a standard deviation (0.63) and medium level, while the total mean of the quality of life among parents of children with autism spectrum disorder was (1.90), a standard deviation (0.34) and medium level.

Results of the second question: Is there any statistically significant differences $(a=0.05)$ in the level of quality of life among parents of children with autism spectrum disorder due to the relationship with the disabled child? To answer this question, means and standard deviations calculated for the level of quality of life among parents of children with autism spectrum disorder according to the relationship with disabled children, T-test conducted to indicate statistical differences between means, as shown in Table (3). 
Table (3). Means, standard deviations, and "T-test" for the impact of the relationship with disabled children on the level of the quality of life among parents of children with autism spectrum disorder

\begin{tabular}{|c|c|c|c|c|c|c|c|}
\hline Domains & $\begin{array}{l}\text { Relations } \\
\text { hip with } \\
\text { disabled } \\
\text { child }\end{array}$ & No & Mean & St. D & $\begin{array}{c}\text { T-valu } \\
\text { e }\end{array}$ & $\begin{array}{l}\text { Degrees } \\
\text { of } \\
\text { freedom }\end{array}$ & $\begin{array}{l}\text { Sig. } \\
\text { level }\end{array}$ \\
\hline \multirow{2}{*}{$\begin{array}{l}\text { Quality of public } \\
\text { health }\end{array}$} & Father & 51 & 2.07 & .477 & 4.159 & 78 & .000 \\
\hline & Mother & 49 & 1.65 & .437 & & & \\
\hline \multirow{2}{*}{$\begin{array}{l}\text { Quality of family } \\
\text { and social life }\end{array}$} & Father & 51 & 2.05 & .273 & 3.935 & 78 & .000 \\
\hline & Mother & 49 & 1.78 & .345 & & & \\
\hline \multirow{2}{*}{$\begin{array}{l}\text { Quality of } \\
\text { emotions }\end{array}$} & Father & 51 & 2.18 & .429 & 5.243 & 78 & .000 \\
\hline & Mother & 49 & 1.69 & .400 & & & \\
\hline \multirow{2}{*}{$\begin{array}{l}\text { Quality of mental } \\
\text { health }\end{array}$} & Father & 51 & 2.19 & .406 & 4.446 & 78 & .000 \\
\hline & Mother & 49 & 1.81 & .349 & & & \\
\hline \multirow{2}{*}{$\begin{array}{l}\text { Quality of daily } \\
\text { activities }\end{array}$} & Father & 51 & 1.96 & .286 & 2.038 & 78 & .045 \\
\hline & Mother & 49 & 1.82 & .300 & & & \\
\hline \multirow[t]{2}{*}{ Financial status } & Father & 51 & 1.91 & .616 & 3.555 & 78 & .001 \\
\hline & Mother & 49 & 1.44 & .553 & & & \\
\hline \multirow[t]{2}{*}{ Total quality of life } & Father & 51 & 2.08 & .297 & 5.600 & 78 & .000 \\
\hline & Mother & 49 & 1.72 & .276 & & & \\
\hline
\end{tabular}

Table (3) showed no statistically significant differences $(a=0.05)$ due to the impact of the relationship with disabled children in all domains and in the total score, and differences were in favor of the father; suggesting that fathers of children with autism spectrum disorder have more quality of the life than mothers. 
Results of the third question: Are there any statistically significant differences $(a=0.05)$ in the level of quality of life among parents of children with autism spectrum due to the gender of the disabled child? To answer this question, means and standard deviations calculated for the quality of life among parents of children with autism spectrum disorder according to the gender of disabled child, T-test conducted to show statistical differences between the means, as shown in Table (4).

Table (4). means, standard deviations, and T-test for the impact of gender at the level of the quality of life among parents of children with autism spectrum disorder

\begin{tabular}{|c|c|c|c|c|c|c|c|}
\hline Domains & $\begin{array}{c}\text { Gender of } \\
\text { disabled } \\
\text { child }\end{array}$ & No & Mean & St. D & $\begin{array}{c}\text { T-valu } \\
\text { e }\end{array}$ & $\begin{array}{c}\text { Degrees } \\
\text { of } \\
\text { freedom }\end{array}$ & $\begin{array}{l}\text { Sig. } \\
\text { level }\end{array}$ \\
\hline \multirow{2}{*}{$\begin{array}{l}\text { Quality of public } \\
\text { health }\end{array}$} & Male & 50 & 1.88 & .494 & .225 & 78 & .822 \\
\hline & Female & 50 & 1.85 & .518 & & & \\
\hline \multirow{2}{*}{$\begin{array}{l}\text { Quality of family and } \\
\text { social life }\end{array}$} & Male & 50 & 1.99 & .288 & 1.819 & 78 & .073 \\
\hline & Female & 50 & 1.85 & .374 & & & \\
\hline \multirow[t]{2}{*}{ Quality of emotions } & Male & 50 & 2.02 & .453 & 1.653 & 78 & .102 \\
\hline & Female & 50 & 1.85 & .496 & & & \\
\hline \multirow{2}{*}{$\begin{array}{l}\text { Quality of mental } \\
\text { health }\end{array}$} & Male & 50 & 2.22 & .318 & 5.456 & 78 & .000 \\
\hline & Female & 50 & 1.78 & .402 & & & \\
\hline \multirow{2}{*}{$\begin{array}{l}\text { Quality of daily } \\
\text { activities }\end{array}$} & Male & 50 & 1.99 & .203 & 3.313 & 78 & .001 \\
\hline & Female & 50 & 1.79 & .345 & & & \\
\hline \multirow[t]{2}{*}{ Financial status } & Male & 50 & 1.70 & .585 & .230 & 78 & .819 \\
\hline & Female & 50 & 1.67 & .678 & & & \\
\hline \multirow[t]{2}{*}{ Total quality of life } & Male & 50 & 1.99 & .309 & 2.628 & 78 & .010 \\
\hline & Female & 50 & 1.80 & .343 & & & \\
\hline
\end{tabular}




\section{Macrothink}

International Research in Education

ISSN 2327-5499

2016, Vol. 4, No. 2

Table (4) showed no statistically significant differences $(a=0.05)$ due to the impact of gender of the disabled child on the quality of mental health, quality of daily activities, and the total quality of life, where the differences were in favor of males.

Results of the fourth question: Are there any statistically significant differences $(a=0.05)$ in the level of quality of life among parents of children with autism spectrum disorder attributed to the severity of disability? To answer this question, means and standard deviations for the level of quality of life among parents of children with autism spectrum disorder according to the severity of the disability, as indicated in Table (5).

Table (5). means and standard deviations for the quality of life among parents of children with autism spectrum disorder according to the severity of disability

\begin{tabular}{|c|c|c|c|c|}
\hline Domains & Groups & No. & Mean & St. D \\
\hline \multirow{4}{*}{$\begin{array}{l}\text { Quality of public } \\
\text { health }\end{array}$} & Mild & 32 & 2.13 & .499 \\
\hline & moderate & 35 & 1.78 & .414 \\
\hline & Severe & 33 & 1.68 & .495 \\
\hline & Total & 100 & 1.87 & .503 \\
\hline \multirow{4}{*}{$\begin{array}{l}\text { Quality of family } \\
\text { and social life }\end{array}$} & Mild & 32 & 2.10 & .277 \\
\hline & moderate & 35 & 1.91 & .207 \\
\hline & Severe & 33 & 1.74 & .414 \\
\hline & Total & 100 & 1.92 & .337 \\
\hline \multirow[t]{4}{*}{$\begin{array}{l}\text { Quality of } \\
\text { emotions }\end{array}$} & Mild & 32 & 2.23 & .442 \\
\hline & moderate & 35 & 1.89 & .363 \\
\hline & Severe & 33 & 1.68 & .473 \\
\hline & Total & 100 & 1.94 & .480 \\
\hline Quality of mental & Mild & 32 & 2.26 & .294 \\
\hline
\end{tabular}




\begin{tabular}{|c|c|c|c|c|}
\hline \multirow[t]{3}{*}{ health } & moderate & 35 & 1.99 & .429 \\
\hline & Severe & 33 & 1.75 & .374 \\
\hline & Total & 100 & 2.01 & .422 \\
\hline \multirow[t]{4}{*}{ Daily activities } & Mild & 32 & 2.05 & .187 \\
\hline & moderate & 35 & 1.83 & .279 \\
\hline & Severe & 33 & 1.80 & .357 \\
\hline & Total & 100 & 1.89 & .299 \\
\hline \multirow[t]{4}{*}{ Financial status } & Mild & 32 & 2.00 & .644 \\
\hline & moderate & 35 & 1.55 & .442 \\
\hline & Severe & 33 & 1.49 & .676 \\
\hline & Total & 100 & 1.68 & .628 \\
\hline \multirow[t]{4}{*}{$\begin{array}{l}\text { Total quality of } \\
\text { life }\end{array}$} & Mild & 32 & 2.14 & .283 \\
\hline & moderate & 35 & 1.85 & .246 \\
\hline & Severe & 33 & 1.70 & .330 \\
\hline & Total & 100 & 1.90 & .338 \\
\hline
\end{tabular}

Table (5) indicated ostensible variation in the means and standard deviations of the level of quality of life among parents of children with autism spectrum disorder because of the different groups of severity of the disability variable, one-way analysis of variance conducted to show the statistical differences between means, as shown in table (6) 
Table (6). One-way analysis of variance for the impact of severity of disability on quality of life

\begin{tabular}{|c|c|c|c|c|c|c|}
\hline Domains & Source & $\begin{array}{l}\text { Sum of } \\
\text { squares }\end{array}$ & $\begin{array}{l}\text { Degrees } \\
\text { of } \\
\text { freedom }\end{array}$ & $\begin{array}{c}\text { Mean of } \\
\text { squares }\end{array}$ & F-value & Sig. level \\
\hline \multirow[t]{3}{*}{$\begin{array}{l}\text { Quality of } \\
\text { public health }\end{array}$} & $\begin{array}{l}\text { Between } \\
\text { groups }\end{array}$ & 2.964 & 2 & 1.482 & 6.714 & .002 \\
\hline & Within groups & 16.997 & 97 & .221 & & \\
\hline & Total & 19.962 & 99 & & & \\
\hline \multirow{3}{*}{$\begin{array}{l}\text { Quality of } \\
\text { family and } \\
\text { social life }\end{array}$} & Between & 1.705 & 2 & .853 & 9.023 & .000 \\
\hline & Within groups & 7.275 & 97 & .094 & & \\
\hline & Total & 8.980 & 99 & & & \\
\hline \multirow{3}{*}{$\begin{array}{l}\text { Quality of } \\
\text { emotions }\end{array}$} & Between & 4.164 & 2 & 2.082 & 11.446 & .000 \\
\hline & Within groups & 14.006 & 97 & .182 & & \\
\hline & Total & 18.170 & 99 & & & \\
\hline \multirow{3}{*}{$\begin{array}{l}\text { Quality of } \\
\text { mental health }\end{array}$} & Between & 3.480 & 2 & 1.740 & 12.658 & .000 \\
\hline & Within groups & 10.583 & 97 & .137 & & \\
\hline & Total & 14.062 & 99 & & & \\
\hline \multirow{3}{*}{$\begin{array}{l}\text { Daily activities } \\
\text { of life }\end{array}$} & Between & .984 & 2 & .492 & 6.244 & .003 \\
\hline & Within groups & 6.070 & 97 & .079 & & \\
\hline & Total & 7.054 & 99 & & & \\
\hline \multirow[t]{2}{*}{ Financial status } & Between & 4.126 & 2 & 2.063 & 5.879 & .004 \\
\hline & Within groups & 27.019 & 97 & .351 & & \\
\hline
\end{tabular}




\begin{tabular}{|l|l|c|c|c|c|c|}
\hline & Total & 31.144 & 99 & & & \\
\hline \multirow{2}{*}{$\begin{array}{l}\text { Total quality of } \\
\text { life }\end{array}$} & Between & 2.699 & 2 & 1.350 & 16.451 & .000 \\
\cline { 2 - 7 } & Within groups & 6.318 & 97 & .082 & & \\
\cline { 2 - 7 } & Total & 9.017 & 99 & & & \\
\hline
\end{tabular}

Table (6) showed no statistically significant differences at the significance level $(a=0.05)$ due to the severity of disabilities in all domains and in the total scale, but (Scheffés method) utilized to indicate the statistically significant differences between means, as shown in the table (7).

Table (7). Scheffe method to the impact of the severity of the disability on quality of life

\begin{tabular}{|c|c|c|c|c|c|}
\hline Domains & Groups & Mean & Mild & Moderate & Severe \\
\hline \multirow{3}{*}{$\begin{array}{l}\text { Quality of } \\
\text { public health }\end{array}$} & Mild & 2.13 & & & \\
\hline & Moderate & 1.78 & $.35(*)$ & & \\
\hline & Severe & 1.68 & $.45\left(^{*}\right)$ & .10 & \\
\hline \multirow{3}{*}{$\begin{array}{lr}\text { Quality of } \\
\text { family and } \\
\text { social life }\end{array}$} & Mild & 2.10 & & & \\
\hline & Moderate & 1.91 & .19 & & \\
\hline & Severe & 1.74 & $.36\left(^{*}\right)$ & .17 & \\
\hline \multirow{3}{*}{$\begin{array}{l}\text { Quality of } \\
\text { emotions }\end{array}$} & Mild & 2.23 & & & \\
\hline & Moderate & 1.89 & $.35\left(^{*}\right)$ & & \\
\hline & Severe & 1.68 & $.56(*)$ & .21 & \\
\hline \multirow{3}{*}{$\begin{array}{l}\text { Quality of } \\
\text { mental health }\end{array}$} & Mild & 2.26 & & & \\
\hline & Moderate & 1.99 & $.27(*)$ & & \\
\hline & Severe & 1.75 & $.52(*)$ & .25 & \\
\hline
\end{tabular}




\section{MlMacrothink}

\begin{tabular}{|c|c|c|c|c|}
\hline \multirow{3}{*}{$\begin{array}{l}\text { Daily } \\
\text { activities of } \\
\text { life }\end{array}$} & Mild & 2.05 & & \\
\hline & Moderate & 1.83 & $.22(*)$ & \\
\hline & Severe & 1.80 & $.25(*)$ & .04 \\
\hline \multirow{3}{*}{$\begin{array}{l}\text { Financial } \\
\text { status }\end{array}$} & Mild & 2.00 & & \\
\hline & Moderate & 1.55 & $.45\left(^{*}\right)$ & \\
\hline & Severe & 1.49 & $.51\left(^{*}\right)$ & .05 \\
\hline \multirow{3}{*}{$\begin{array}{l}\text { Total quality } \\
\text { of life }\end{array}$} & Mild & 2.14 & & \\
\hline & Moderate & 1.85 & $.30\left(^{*}\right)$ & \\
\hline & Severe & 1.70 & $.45\left(^{*}\right)$ & .15 \\
\hline
\end{tabular}

\section{*Significant at the significance level $(a=0.05)$.}

Table (7) showed statistically significant differences $(\mathrm{a}=0.05)$ between mild disability on the one hand and each of the moderate and severe on the other hand, where differences were in favor of the mild group of public health quality, the quality of the emotions, the quality of mental health, activities of daily life, financial status, and total quality of life. There were statistically significant differences $(\mathrm{a}=0.05)$ between the mild and severe disability, where differences were in favor of the mild group in the quality of family and social life.

\section{Discussion}

-The results of the current study showed that the level of quality of life among parents of children with autism spectrum disorder was medium. This is attributed to the fact that the presence of a disabled child in the family serves as a source of problems and psychological pressures felt by parents; where a disabled child care requires a great effort and financial requirements from parents exceed that of provided for normal children, and all this makes parents unable to bear the psychological, economic and social needs of a child with autism spectrum disorder; which is reflected on the quality of their lives.

The current results are consistent with the results of DeGrace and Imms (2006), which showed that the level of quality of life among the families of children with autism spectrum disorder was medium, as well as Lundy (2011), which showed that the level of quality of life among the families of children with autism spectrum disorder was medium, while the current results disagreed with the results of Yamada, et al (2012), which showed low level of the quality of life among families of children with pervasive developmental disorders. The study of Dardas and Ahmed (2014) confirmed that the level of quality of life among the families of 
children with autism spectrum disorder was low, the same result shown in Perumal, et al (2014), which showed that the level of quality of life among the families of children with autism spectrum disorder was low.

-The current study showed statistically significant differences in the level of quality of life and its domains among the participants due to the impact of the relationship with disabled children, where differences were in favor of the fathers. This finding can be justified in the light of the ability of parents to control their emotions and awareness and their self-control as they are responsible for raising the children and running the household, this may be attributed to the ability of men to take responsibility towards the family. This can also be justified in the light of mothers' link and connection with their children and their responsibility for them, and the suffering they have from training their child on the social and communicative skills and interaction with the community, where the autistic disability results in unfamiliar behaviors such as stereotypical behaviors and defecation disorders, sleep disorders, eating disorders and self-mischief, and other attempts to put on and take off clothes, hence mothers facing extreme difficulties in controlling of these behaviors, which contribute to reducing the level of quality of life among them.

The current results are consistent with the results of Hartley, et al (2012), which confirmed the existence of differences in the level of quality of life due to the relationship to children with autism spectrum disorder in favor of the fathers, while it disagreed with the study of Dardas and Ahmad (2014), which showed no differences in the level of quality of life due to the variable of relationship to children with autism spectrum disorder.

-The current results showed statistically significant differences in the level of quality of life among the participants due to the impact of gender of the autistic child, where differences were in favor of males. This can be explained due to the fact that the birth of female child with autism spectrum disorder in the family causes a state of anxiety and fear for the future among the parents compared to birth of male child with autism spectrum disorder.

-Results showed statistically significant differences in the level of quality of life and its domains among the participants due to the impact of severity of disability, where differences were in favor of the mild group. The current results can be justified in light of the presence of a disabled child in the family of severe and moderate disability is a source of pressure for the family and preventing them from practicing their activities of daily life, where their care and requirements are different compared to those of mild disability. As well as the needs of the various requirements of the different devices representing a source of psychological pressures, which are reflected at the level of psychological and physical health of the parents, in addition to the extra-financial burden. The current results are consistent with the results of DeGrace and Imms (2006), which showed differences in the level of quality of life due to the variable of severity of the disability in favor of the families of children with mild disability. Kheir, et al (2012) is also consistent with the current study, where it showed differences in the level of quality of life for families of children with autism due to the severity of autism spectrum disorder in favor of the mild disorder. 


\section{Recommendations}

In light of the conclusions reached, the author made a set of recommendations summarized as follows:

1. The need to draw the attention of officials in the care and service centers for children with autism spectrum to provide training programs and activities for parents of autistic children to improve the level of quality of life, especially mothers.

2. The need to direct charity and cooperative societies and businessmen to provide financial and economic support for families of children with moderate and severe disabilities; to ensure they are provided all the requirements and needs of their children to ensure a better level quality of life.

3. Taking into account the media respects regarding quality of life among parents of children with autism spectrum disorder to contribute to life satisfaction and happiness.

4. Conducting comparative studies between parents of children with autism spectrum disorder and normal children.

\section{References}

Abdel-Fattah, Fawqya; Hussein, Mohammed (2006), family and school factors predicting quality of life among children with learning difficulties in Beni Suef, The $4^{\text {th }}$ Scientific Conference of the Faculty of Education in Beni Suef "The role of the family and civil society institutions in the discovery and care for people with special needs, May 3 to 4.

Abdul Qadir, Ashraf. (2013). The effectiveness of early intervention in improving the quality of life among families of autistic children. A paper submitted to the $13^{\text {th }}$ forum "Gulf Disability Society, under the slogan, Early Intervention-investment for the future", April 2-4, 2013, Manama, Bahrain.

Abdullah, Rania. (2014). The effectiveness of a guiding program to improve the quality of life among families of hearing disabled children. Journal of the College of Education-Banha University, Egypt, 99 (1), 425 to 446.

Abu Halawa, Muhammad. (2010). Quality of life, the concept and dimensions. A paper submitted to the Seventh Scientific Conference of Faculty of Education, University of Kafr El-Sheikh, entitled "Quality of life as an investment for Educational and Psychological Sciences, 13-14 / 4/2010.

Adli, Kazim. (2006). Extent of quality of life among students of the Faculty of Education and its relationship with some variables, Proceedings of the Symposium of Psychology and Quality of Life, Sultan Qaboos University, the Sultanate of Oman.

Alashwal, Adel. (2005). The quality of life from the social, psychological and medical perspective, in the third scientific conference: "psychological and educational development of the Arab people in the light of the quality of life", Faculty of Education, the University of Zagazig 15-16 March. 
Alkhonji, Khaled. (2006): Positive Psychology and improvement of life. Sultan Qaboos University, the Sultanate of Oman.

Antle, B. (2005) A Family's Adaptation to A Child's Blindness. Journal of Visual Impairment \& Blindness, 99 (4): 209-2018.

Bonomi, R.E., Patrick, D.L. \& Bushnel,D.M. (2000).Validation of The United States Version Of Assessment International Perspectives, Berlin : Springer-Verlag. (Pp, 41-57).

Dardas , L, Ahmad, M. (2014). Quality of life among parents of children with autistic disorder: A sample from the Arab world. Research in Developmental Disabilities, 35 : 278287.

DeGrace, B and Imms, C. (2006). Daily Activities of Families with a child with Severe Autism Revolved Around the need to Occupy and Pacify the Child: Families Felt Robbed of Meaning and Satisfaction in Family Life. Australian Occupational Therapy Journal, 53, 136-140.

Eraqa, Mohammed Salahuddin. (2006). The effectiveness of a guiding program for parents to improve the quality of life for children with special needs. Journal of the College of Education-Banha University, Egypt, 16 (22), 218 to 258.

Hartley, S., Braker, E., Baker, J., Seltzer, M. and Greenberg, J. (2012). Marital Satisfaction and Life Circumstances of Grown Children with Autism Across (7) Years. Journal of Family Psychology, 26(5), 688-697.

Institute of Allied Health Sciences and, Department of Nursing, National Cheng Kung University, Taiwan. (2009). Quality of life of family caregivers of children with autism, The mother's perspective, autism. SAGE Publications and The National Autistic Society . 13(1) $81-91$.

Iraqi, Salahuddin; Mazloum, Ramadan. (2005). The effectiveness of a guiding program to improve the quality of life in depressed students. Journal of the Faculty of Education, Tanta University, 2 (34), 468 to 509.

Kheir, N., Ghoneim, O., Sandridge, A., Al-Islmil, M., Hayder, S. and Al-Rawi, F. (2012). Quality of Life of Caregivers of Children with Autism in Qatar. The International Journal of Research and Practice, 16, (3), 293-298.

Lee, ., Harrington, R., Louie, B.. \& Schaffer, C. (2008). Children with autism: Quality of life and parental concerns. Journal of Autism and Developmental Disorders ,38,1147-1160.

Lundy, H. (2011). Parental Stress, Socioeconomic Status, Satisfaction with Services, and Family Quality of Life among Parents of Children Receiving Special Education Services. ProQuest LLC, Ph.D. Dissertation, Georgia State University.

Magdi, Hanan. (2009). Social support and its relationship to the quality of life among patients with diabetes, unpublished Master Thesis, Egypt: Zagazig University. 


\section{Macrothink}

International Research in Education

ISSN 2327-5499

2016, Vol. 4, No. 2

Mohammed Saeed. (2011). Quality of life and coexistence strategies (confrontation) for the Deaf and the Hearing Impaired: An analytical study. Journal of the College of Education in Banha, 87 (2), 217 to 250.

Nina I. Zuna, James P. Selig, Jean Ann Summers and Ann P. (2009). Confirmatory Factor Analysis of a Family Quality of Life Scale for Families of Kindergarten Children Without Disabilities, Journal of Early Intervention, 2 (31): 111-125.

Park, J., Hoffman, L., Marquis, J., Turnbull, A. P., Poston, D., Mannan, H., Wang, M. \& Nelson, L. L. (2003). Toward assessing family quality outcomes of service delivery: validation of a family quality of life survey. Journal of Intellectual Disability Research, 47 (4): 367-384.

Perumal,V ,Vimala V,Om Prakash L. (2014): Quality of life in families of children with autism spectrum disorder in India. Journal of Pharmacy Research, 8(6):791-797.

Reine, G. Lancon. C, tucci, S, Sapin. C, and Auquier, p .(2003). Depression and subjective Quality of life in chronic phase schizophrenic patients. Act psychiatrica scandinavica. (108)..297-303.

Taha, Najat. (2013). The quality of the life among parents and its relationship with happiness of their deaf children. journal Psychology, Egypt, 26 (97), 152 to 155.

Yamada, A, Misuzu, K, Miyoshi, S, Masako, S., Norio W, Tatsuo, A and Toshi A. (2012) . Quality of life of parents raising children with pervasive developmental disorders, $B M C$ Psychiatry, 12: 119-131.

\section{Copyright Disclaimer}

Copyright reserved by the authors.

This article is an open-access article distributed under the terms and conditions of the Creative Commons Attribution license (http://creativecommons.org/licenses/by/3.0/). 